\title{
ASPECTOS DA HISTÓRIA DO ENSINO DE LITERATURA NOS PERIÓDICOS ACADÊMICOS BRASILEIROS'
}

\section{ASPECTS OF THE HISTORY OF TEACHING OF LITERATURE IN THE BRAZILIAN ACADEMIC JOURNALS}

\author{
Sérgio Fabiano Annibal² \\ Gabriel Bosco Vaz da Silva ${ }^{3}$
}

\begin{abstract}
RESUMO: Apresentamos resultados do mapeamento de artigos que tratam das tendências do ensino de literatura nas revistas Educação e pesquisa e Leitura: teoria e prática, no período de 1997 a 2016. Estabelecemos categorias para localizar melhor essas tendências, além de apontar teóricos com mais recorrência em cada uma dessas três categorias. Utilizamos abordagem qualitativa por meio de Análise Documental. Notamos predomínio de publicações sobre o tema no Sudeste/Exterior; em menor número no Centro Oeste e Sul. Finalmente, visualizamos as tendências nas movimentações do campo da Educação e das Letras, no que tange ao ensino de literatura e à formação de professores.

Palavras-chave: Formação de professores. Ensino de literatura. Campo educacional.
\end{abstract}

ABSTRACT: We present some results of the mapping of articles that deal with the tendencies of literature teaching in the journals Educação $e$ pesquisa and Leitura: teoria e prática since 1997 untill 2016. We established categories to locate these trends and theoreticians with more recurrence in these categories. We use a qualitative approach through Document Analysis. We have a predominance of publications on the subject in the Brazilian Southeast and Foreign country; and smaller number in the Center West and South of Brazil. Finally, we visualize tendencies in the movements of those fields, reffers to teaching of literature and teacher education.

Keywords: Teacher education. Literature teaching. Field education. Academic magazines.

\footnotetext{
${ }^{1}$ Artigo recebido em 30/03/2019 e aprovado em 30/05/2019.

2 Doutor em Educação, Mestre em Estudos Literários e Graduado em Letras pela UNESP/Brasil; Pós-Doutor pela Université de Cergy-Pontoise/França; Professor de Didática e Orientador no Programa de Pós-Graduação em Letras e no ProfLetras na UNESP/Brasil; Líder do Grupo de Estudos e Pesquisas sobre Linguagem, Ensino e Narrativas de Professores - Geplenp UNESP/Brasil; e-mail: sergio.annibal@unesp.br.

${ }^{3}$ Graduado em Letras pela UNESP/Brasil; Membro do Grupo de Estudos e Pesquisas sobre Linguagem, Ensino e Narrativas de Professores - Geplenp - UNESP/Brasil; e-mail: gabrielbvs@gmail.com.
} 


\section{Introduçăo}

Este artigo visa apresentar resultados da investigação intitulada "Formação de Professores em Letras: o ensino de literatura em periódicos brasileiros", financiada pela Fundação de Amparo à Pesquisa do Estado de São Paulo - FAPESP (Proc. 2016/12706-3). O estudo se centra no mapeamento de artigos sobre ensino de literatura nos periódicos Educação e pesquisa e Leitura: teoria e prática, no período de 1997 a 2016.

A importância do levantamento das tendências do ensino de literatura em revistas científicas consiste em perceber aspectos do campo (BOURDIEU, 1983) da Educação e das Letras, o que implica levar em consideração o que se tem produzido sobre o ensino de literatura; quais são as principais metodologias e quais são os referenciais teóricos mais utilizados na composição de um discurso a respeito do ensino de literatura em periódicos brasileiros.

Ao discutir esse tema nas Letras, especificamente, na literatura é preciso reconhecer que o diálogo tem que ser realizado com a Educação, pois, a literatura é objeto, no entanto, ultrapassa as discussões circunscritas à critica literária, à teoria ou à história da literatura e adentra pelos domínios do ensino e da aprendizagem deste objeto específico; com isso, a porosidade dos campos, característica geral para se pensar os campos do conhecimento, segundo Bourdieu (1983), vêm à baila, à medida que particularidades do campo da Educação e das Letras são mobilizadas não para um público especializado de críticos e teóricos da literatura, mas por professores e seus alunos que têm o desafio da materialidade do texto literário em suas mãos.

\section{0 ensino de literatura nos periódicos brasileiros}

Com a finalidade de indagar o que se tem produzido sobre o ensino de literatura nos periódicos Educação e pesquisa e Leitura: teoria e prática (de 1997 a 2016), nosso questionamento inicial consistiu em quais metodologias adotar para abordar os artigos das revistas. Para isso, realizamos o levantamento de pesquisas realizadas por acadêmicos brasileiros e do exterior que trazem em comum a preocupação de estudar a produção científica. 
A potencialidade da produção acadêmica é uma grande questão para pesquisadoras como Catani, Vilhena e Ferreira, cujas contribuições sobre o estudo de periódicos acadêmicos utilizamos neste resultado de pesquisa. A partir das contribuições de Catani e Vilhena (1992), por exemplo, elaboramos um repertório analítico para o estudo e catalogação dos artigos levantados nas revistas Educação e Pesquisa e Leitura: teoria e prática.

No que tange, especificamente, ao estudo de revistas, Catani \& Vilhena (1992) enfatizam sobre a potencialidade das revistas e a importância do acesso e resgate dos dados produzidos no decorrer da investigação. A preocupação das autoras é com as revistas de ensino e no caso desse estudo a preocupação é com revistas acadêmicas/científicas, mas o que nos interessa, neste caso, é esta potencialidade que este tipo de estudo oferece para se compreender mais como os agentes dos campos reagem com os fluxos teóricos e metodológicos do debate acadêmico, no período de 1997 a 2016. Sendo assim, reiteramos a relevância desse tipo de corpus pelas palavras das autoras:

[...] acompanhar o aparecimento e o ciclo de vida dessas revistas permite conhecer as lutas por legitimidade, que se travam no campo educacional. É possível analisar a participação dos agentes produtores do periódico na organização do sistema de ensino e na elaboração dos discursos que visam a instaurar as práticas exemplares (CATANI \& VILHENA, 1992, p. 117-118).

As pesquisadoras afirmam a importância da organização dos dados, da construção do "repertório analítico e catálogos de referências básicas" para utilização na pesquisa. Desse modo, tendo em vista a importância do acesso aos dados, elas propõem que seja realizado esse trabalho, isto é, organização e resgate da imprensa pedagógica periódica e que seja norteado por duas diretrizes: a primeira consiste em uma investigação que parte do ponto de vista histórico, ou seja, na criação dos "repertórios analíticos", que tem como objetivo informar sobre os conteúdos dos periódicos, registrar seu ciclo de vida e informações sobre seus colaboradores, assim como seus leitores, que compõem as movimentações do periódico. A segunda consiste no estudo específico ao "próprio periódico e sua produção", sendo possível a reconstrução, em um

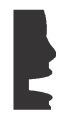

\begin{tabular}{l|l} 
Interdisciplinar, São Cristóvão, v. 31, jan.-jun., p. 25-41, 2019. & 27
\end{tabular} 
momento específico, do funcionamento e estruturação da revista, possibilitando o entendimento dos "movimentos" e da natureza das disputas dos agentes que compõem o campo.

Ao partir das contribuições de Catani e Vilhena (1992), propomos mapear as ocorrências sobre o ensino de literatura nos artigos levantados nas duas revistas acadêmicas, de 1997 a 2016. Como os artigos catalogados possuem distintos assuntos nesses dezenove anos de estudo, aplicamos os seguintes descritores a fim de melhor selecioná-los: ensino de literatura; literatura e ensino; ensino de literatura e tecnologias; ensino de literatura e mídias; literatura e mídias; ensino de literatura e formação de leitores; ensino literário e letramento literário.

É importante destacar que a seleção dos artigos não levou somente em conta a leitura dos títulos, mas também análise dos resumos, palavras-chave, assim como das considerações finais. Isso se justifica pela possibilidade de acessar um maior número de textos, sendo que alguns artigos não trazem, explicitamente, no título, a temática ensino de literatura, o que comprova a diversidade de abordagens a respeito da literatura e seu ensino.

A análise dos artigos, por sua vez, sucedeu-se a partir de alguns aspectos específicos, a fim de aperfeiçoar a apreensão dos conteúdos, isto é, optamos por realizar apreciação dos resumos e das considerações finais dos artigos com o intuito de compreender os discursos propagados nas revistas científicas a respeito do ensino de literatura. Essa metodologia empregada baseia-se nas fundamentações teóricas e metodológicas de Norma Sandra de Almeida Ferreira (2002), às quais refletem acerca da relevância das pesquisas denominadas "estado de arte" e "estado do conhecimento". Tais pesquisas (de caráter bibliográfico) possuem em comum o desafio de mapear e descrever o estado atual de uma determinada área de pesquisa: o que se tem produzido a respeito de um dado conhecimento, quais as principais lacunas, onde se encontram os principais entraves teóricos e/ou metodológicos:

Definidas como de caráter bibliográfico, elas parecem trazer em comum o desafio de mapear e de discutir uma certa produção acadêmica em diferentes campos do conhecimento, tentando responder que aspectos e dimensões vêm sendo destacados e privilegiados em diferentes épocas e lugares, de que 
formas e em que condições têm sido produzidas certas dissertações de mestrado, teses de doutorado, publicações em periódicos e comunicações em anais de congressos e de seminários. Também são reconhecidas por realizarem uma metodologia de caráter inventariante e descritivo da produção acadêmica e científica sobre o tema que busca investigar, à luz de categorias e facetas que se caracterizam enquanto tais em cada trabalho e no conjunto deles, sob os quais o fenômeno passa a ser analisado (FERREIRA, 2002, p.258).

Nesse sentido, Ferreira (2002) aponta a diferença entre as pesquisas do "estado da arte" e do "estado do conhecimento". A primeira equivale ao estudo de dissertações de mestrado e teses de doutorado. A segunda trata da análise de artigos de periódicos e publicações de comunicações em anais de congressos e de seminários. Diante disso, ressaltamos que esse estudo está inserido no campo das pesquisas do "estado do conhecimento" pelo fato de apresentar o objetivo de mapear artigos sobre o ensino de literatura.

Em sua tese de doutorado, "Pesquisa em leitura: Um estudo dos resumos de dissertações de mestrado e teses de doutorado defendidas no Brasil, de 1980 a 1995" (1999), Ferreira realiza a leitura de dados bibliográficos, títulos e resumos de 189 dissertações de mestrado e teses de doutorado sobre Leitura defendidas nos programas de Pós-Graduação em Educação, Psicologia, Biblioteconomia, Letras/Linguística e Comunicação.

Por meio desse estudo, Ferreira (1999) pondera ser possível organizar e interrogar uma produção a respeito da leitura no Brasil: a partir da análise de cada resumo levantado, torna-se possível propor tendências e detectar ênfases durante o processo de composição do discurso acadêmico em relação à leitura.

Apoiada na noção de gênero discursivo de Bakhtin (1997), Ferreira (2002) define o resumo como um dos gêneros do discurso relacionado ao campo acadêmico, com certas particularidades de produção e finalidades específicas. O resumo é tido como um "enunciado estável" determinado pelos agentes produtores, pela noção de acabamento do texto e pela relação dos parceiros comprometidos no processo de elaboração e recepção.

Desse modo, a partir das contribuições de Catani \& Vilhena (1992)

e Ferreira (1999), buscamos na análise dos resumos e das considerações 
finais ter uma visão panorâmica, com o intuito de mapear as tendências do que vem sendo discutido a respeito do ensino de literatura nas revistas científicas, no que se refere aos anos de 1997 a 2016.

Com a finalidade de observar os aspectos de cada um dos textos, elaboramos um protocolo de leitura em periódicos, contendo as seguintes informações: título do periódico, título do artigo, autor, ano de publicação, filiações, resumo original, palavras-chave. Com essa organização tem-se uma base geral do corpus, indicando os caminhos percorridos no interior do campo para se debater a questão e, com isso, se percebe as tendências (o que se pensava, quais eram as preocupações, qual tônica dos discursos) acerca do texto literário e sua abordagem pedagógica. Todavia, por meio desse protocolo elaboramos um quadro com a relação dos títulos dos artigos, data de publicação, nomes dos autores e as suas filiações institucionais:

Relação dos artigos levantados em Educação e Pesquisa e Leitura: teoria e prática Educação e pesquisa

1. Vãs querelas e verdadeiros objetivos do ensino da literatura na França (2007), de Jean Varrier (Université Paris 8, França), Tradução de Neide Luzia de Rezende (Universidade de São Paulo);

2. Literature and communicative competence: a wrong assorted matrimony? (2014), de Ximena Troncoso Araos (universidade Católica de Maule, Talca, Chile);

3. Formador de leitores, formador de professores: a trajetória de Max Butlen (2015) entrevista com Max Butlen realizada (Cergy-Pontoise, França) por Belmira Oliveira Bueno e Neide Luzia de Rezende, doutoras da Faculdade de Educação da Universidade de São Paulo (FEUSP);

4. O Partido Conservador e a educação literária no Império brasileiro 1841-1863 (2015), de Luiz Eduardo Oliveira (Universidade Federal de Sergipe, São Cristóvão, Sergipe).

Leitura: teoria e prática

1. A leitura e o espaço do prazer: um estudo sobre as práticas docentes (1997), de Angela da Rocha Rolla (Pontifícia Universidade Católica do Rio Grande do Sul);

2. A "leitura literária" e a outra nas vozes do currículo e dos programas (2005), de Antônio Branco (Universidade do Algarve, Faro, Portugal);

3. O ensino de literatura: ler, ouvir, colaborar e conhecer ou "O testamento de Clara" (2006), de Marly Amarilha (Universidade Federal do Rio Grande do Norte); 4. Literatura e ensino: notas quixotescas da fronteira (2008), de Maria do Rosário Longo Mortatti (Universidade Estadual Paulista, Marília, São Paulo);

5. Ensino de literatura: a hora e a vez do leitor (2009), de Reginaldo Clecio dos Santos (Universidade Federal de Pernambuco, Recife, Pernambuco);

6. Audiolivro: um suporte para a educação literária (2010), de Maria Salete Daros de Souza, Rubia Aparecida Celva e Vanessa Helvadjian (Centro Universitário de Brusque - Unifebe Santa Cantarina);

7. Enseñanza de la literatura: de teorías y lecturas (2010), de Carolina Cuesta (Universidad Nacional de la Plata, Argentina); 
8. Um problema de formação: reflexões sobre literatura, leitura e ensino (2011), de Renato Suttana (Universidade Federal da Grande Dourados, Mato Grosso do Sul);

9. Escola e leitura: Carlos Drummond de Andrade no livro didático (2012), de Maria Amélia Dalvi (Universidade Federal do Espírito Santo - Espírito Santo);

10. Por um ensino literário complexo (2014), de Francisco Neto Pereira Pinto (Pontifícia Universidade Católica de Campinas, Campinas, São Paulo, Brasil);

11. Letramento inicial na formação inicial do professor (2015), de Maria Aparecida Lopes Rossi e de Selma Martines Peres (Universidade Federal de Goiás, Regional Catalão, Catalão, Goiás);

12. As dicotomias da leitura na educação básica: reflexões sobre o "literário" e o "não literário" (2016), de Ana Paula dos Santos de Sá (Universidade Estadual de Campinas, Campinas, São Paulo);

13. Literatura na Educação Infantil: modos de trabalho com textos e possibilidades do desenvolvimento da capacidade criativa (2016), de Larissa Elizabeth Barros Brito e Maria Sílvia Pinto de Moura Librandi da Rocha (Pontifícia Universidade Católica de Campinas, Campinas, São Paulo).

Fonte: (SILVA, 2018)

A partir desse quadro, quantificamos os artigos e os sistematizamos tematicamente, no período de 1997 até 2016 . Notamos que Educação e Pesquisa apresenta um número menor de artigos que tratam do tema ensino de literatura em comparação com Leitura: teoria e prática. $\mathrm{O}$ primeiro periódico apresenta quatro artigos e o segundo apresenta treze artigos que abordam a temática estudada, isso se justifica pelo fato de Educação e Pesquisa não se restringir, especificamente, na Educação, às discussões sobre leitura; diferentemente de Leitura: teoria e prática, que tem como principal objetivo a circulação de pesquisas no campo de leitura.

Por meio do quadro que vem a seguir, nos atentamos às filiações institucionais dos autores dos textos mapeados. No período de 1997 a 2016, temos cinco ocorrências de estrangeiros e cinco de brasileiros da região Sudeste do Brasil; três no Nordeste, duas no Centro-oeste e duas na região Sul. Logo, notamos uma predominância nas filiações de autores, nos dois periódicos, estrangeiros e da região Sudeste (10 artigos de um total de 17) e apenas 7 textos divididos entre autores das regiões Nordeste, Centro-oeste e Sul: 
Recorrência de publicação por região (Autor, ano de publicação e filiação institucional)

\begin{tabular}{|c|c|c|c|c|}
\hline Exterior & Sudeste & Nordeste & Centro Oeste & Sul \\
\hline $\begin{array}{l}\text { (VARRIER, } \\
\text { 2007), } \\
\text { Université } \\
\text { Paris 8, } \\
\text { França. }\end{array}$ & $\begin{array}{l}\text { (MORTATTI, } \\
\text { 2005), } \\
\text { Universidade } \\
\text { Estadual } \\
\text { Paulista, } \\
\text { Marília, São } \\
\text { Paulo. }\end{array}$ & $\begin{array}{l}\text { (OLIVEIRA, } \\
\text { 2015), } \\
\text { Universidade } \\
\text { Federal de } \\
\text { Sergipe, São } \\
\text { Cristóvão, } \\
\text { Sergipe. }\end{array}$ & $\begin{array}{l}\text { (SUTTANA, } \\
\text { 2011), } \\
\text { Universidade } \\
\text { Federal da } \\
\text { Grande } \\
\text { Dourados, Mato } \\
\text { Grosso do Sul }\end{array}$ & $\begin{array}{l}\text { (ROLLA, } \\
\text { 1997), } \\
\text { Pontifícia } \\
\text { Universidade } \\
\text { Católica do } \\
\text { Rio Grande do } \\
\text { Sul }\end{array}$ \\
\hline $\begin{array}{l}\text { (ARAOS, } \\
\text { 2014), } \\
\text { Universidade } \\
\text { Católica de } \\
\text { Maule, } \\
\text { Talca, Chile. }\end{array}$ & $\begin{array}{l}\text { (DALVI, } \\
\text { 2012), } \\
\text { Universidade } \\
\text { Federal do } \\
\text { Espírito } \\
\text { Santo, } \\
\text { Espírito } \\
\text { Santo. }\end{array}$ & $\begin{array}{l}\text { (AMARILHA, } \\
\text { 2006), } \\
\text { Universidade } \\
\text { Federal do Rio } \\
\text { Grande do } \\
\text { Norte, Natal, } \\
\text { Rio Grande do } \\
\text { Norte. }\end{array}$ & $\begin{array}{l}\text { (ROSSI/ } \\
\text { PERES, 2015), } \\
\text { Universidade } \\
\text { Federal de } \\
\text { Goiás, Regional } \\
\text { Catalão, } \\
\text { Catalão, Goiás }\end{array}$ & $\begin{array}{l}\text { (SOUZA; } \\
\text { CELVA; } \\
\text { HELVADJIAN) } \\
\text { Centro } \\
\text { Universitário } \\
\text { de Brusque, } \\
\text { Santa } \\
\text { Cantarina }\end{array}$ \\
\hline $\begin{array}{l}\text { (BUTLEN, } \\
\text { 2015), } \\
\text { Cergy- } \\
\text { Pontoise, } \\
\text { França. }\end{array}$ & $\begin{array}{l}\text { (PINTO, } \\
\text { 2014), } \\
\text { Pontifícia } \\
\text { Universidade } \\
\text { Católica de } \\
\text { Campinas, } \\
\text { Campinas, } \\
\text { São Paulo. }\end{array}$ & $\begin{array}{l}\text { (SANTOS, } \\
\text { 2009), } \\
\text { Universidade } \\
\text { Federal de } \\
\text { Pernambuco, } \\
\text { Recife, } \\
\text { Pernambuco }\end{array}$ & & \\
\hline $\begin{array}{l}\text { (BRANCO, } \\
\text { 2005), } \\
\text { Universidade } \\
\text { do Algarve, } \\
\text { Faro, } \\
\text { Portugal. }\end{array}$ & $\begin{array}{l}\text { (DE SÁ, } \\
\text { 2016), } \\
\text { Universidade } \\
\text { Estadual de } \\
\text { Campinas, } \\
\text { Campinas, } \\
\text { São Paulo. }\end{array}$ & & & \\
\hline $\begin{array}{l}\text { (CUSTA, } \\
\text { 2010), } \\
\text { Universidad } \\
\text { Nacional de } \\
\text { la Plata, } \\
\text { Argentina }\end{array}$ & $\begin{array}{l}\text { (BRITO; } \\
\text { ROCHA, } \\
\text { 2016), } \\
\text { Pontifícia } \\
\text { Universidade } \\
\text { Católica de } \\
\text { Campinas, } \\
\text { Campinas, } \\
\text { São Paulo. } \\
\end{array}$ & & & \\
\hline
\end{tabular}

Em seguida, no sentido de enfatizar a distribuição dos autores e do tema ensino de literatura nas diferentes regiões do país bem como as contribuições estrangeiras, por meio dos dois periódicos acadêmicos em análise, apresentamos um gráfico com a distribuição dos autores por região. Dos dezessete artigos levantados, temos os seguintes números: Exterior 
31\% (cinco artigos); Sudeste 31\% (cinco artigos); Nordeste 18\% (três artigos); Centro-Oeste 12\% (dois artigos); Sul 12\% (dois artigos).

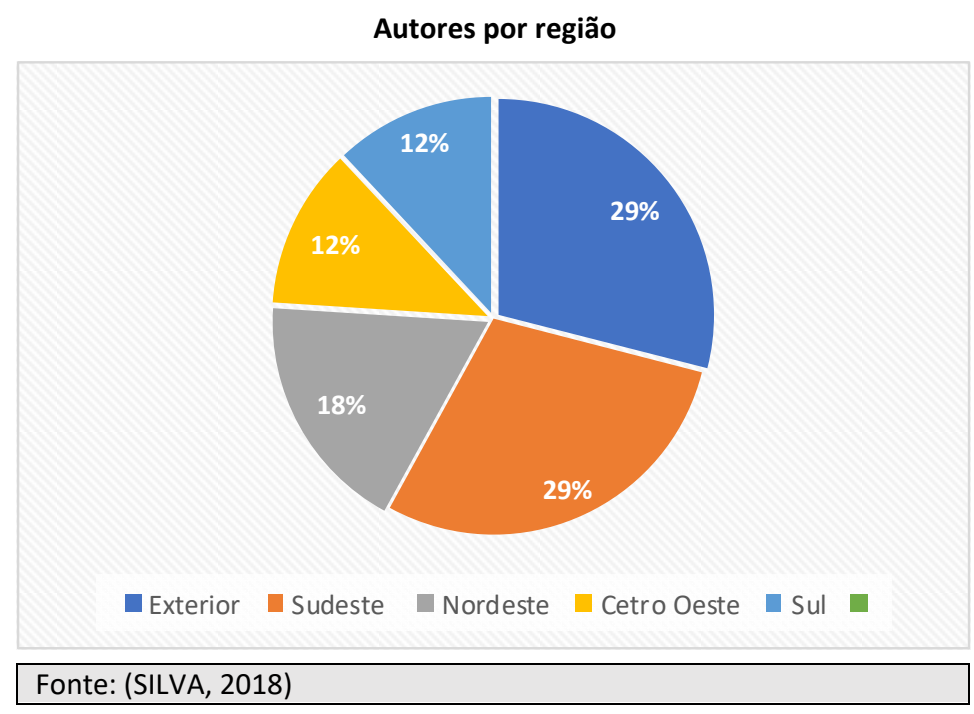

A relevância desse procedimento quantitativo foi a de assinalar a distribuição de autores, seus respectivos centros de pesquisa e, sobretudo, suas contribuições na composição de uma formação discursiva a respeito do ensino de literatura no país e no exterior. Portanto, consistiu em reconhecer as instituições e sua parcela na construção de um estado do conhecimento acerca da literatura e seu ensino.

Já no sentindo de levantar tendências do ensino de literatura, realizamos a categorização dos dados dos artigos selecionados para análise. Para isso, buscamos na análise do conteúdo métodos e metodologias, a fim de perceber tendências do ensino de literatura e, com isso, elaborar categorias presentes nos periódicos. A análise do conteúdo consiste em um método de estudo que visa extrair sentido de textos em suas mais diversas manifestações linguísticas; é um conjunto de instrumentos metodológicos que se aplicam aos discursos/conteúdos. (BARDIN, 1977, p.10).

A categorização se deu a partir da apreciação dos enunciados que compõem os títulos, as palavras-chave, os resumos e as considerações finais dos artigos levantados. Isso se justifica pela possibilidade de apreender uma formação discursiva como discutida em Maingueneau, apoiado por Pêcheux (2015, p. 81-82) de um corpus; e, por meio de organização metodológica 
empreendida neste artigo, divulgar os enunciados que contribuem para uma formação ideológica do que consiste em ensinar literatura.

Portanto, a partir da relação dos temas (descritores) ensino de literatura, literatura e ensino, ensino de literatura e tecnologias, ensino de literatura e mídias, literatura e mídias, ensino de literatura e formação de leitores, ensino literário e letramento literário, buscamos divulgar a presença desses enunciados e, diante disso, perceber aspectos do campo educacional/literário (enquanto um espaço social comum marcado por um jogo de forças, no qual há produtores de um discurso a respeito do ensino de literatura), expressos nas revistas científicas.

Em seguida, apresentamos uma grelha ${ }^{4}$ para levantamento e apreciação dos dados dos artigos mapeados:

\section{Grelha de categorização de artigos}

\begin{tabular}{|l|l|l|l|l|}
\hline Título do artigo mapeado & Título & $\begin{array}{l}\text { Palavras- } \\
\text { chave }\end{array}$ & Resumo & $\begin{array}{l}\text { Considerações } \\
\text { finais }\end{array}$ \\
\hline $\begin{array}{l}\text { Descritores para seleção dos } \\
\text { artigos nas revistas } \\
\text { científicas }\end{array}$ & & & & \\
\hline Ensino de literatura & $(\mathrm{X})$ & & & \\
\hline Literatura e ensino & & & & \\
\hline $\begin{array}{l}\text { Ensino de literatura e } \\
\text { tecnologias }\end{array}$ & & & \\
\hline Ensino de literatura e mídias & & & & \\
\hline $\begin{array}{l}\text { Ensino de literatura e } \\
\text { formação de leitores }\end{array}$ & & & \\
\hline $\begin{array}{l}\text { Ensino literário e letramento } \\
\text { literário }\end{array}$ & \multicolumn{3}{|l|}{} \\
\hline (X) número de ocorrência dos descritores nos artigos levantados \\
\hline Fonte: (SILVA, 2018) & & \\
\hline
\end{tabular}

A partir da aplicação dessa grelha em cada um dos artigos levantados, tornou-se possível realizar uma apreciação dos conteúdos desses textos (títulos, palavras-chave, resumos e considerações finais) e,

\footnotetext{
${ }^{4}$ Optamos por manter grelha pelo fato de Luís Antero Reto e Augusto Pinheiro trazerem na tradução de L'Analyse de Contenu (1977), de Bardin, este termo. A obra apresenta diversos modelos de grelhas aplicadas em textos em suas mais diversas manifestações. Sendo assim, a grelha utilizada nesse estudo, por sua vez, foi inspirada nos exemplos metodológicos de Bardin para o estudo de textos.
} 
com isso, levantar categorias do ensino de literatura nas revistas Educação e pesquisa e Leitura: teoria e prática.

Com essa sistematização, foram verificadas as seguintes categorias do ensino de literatura nos periódicos:

\section{Categorias encontradas nos artigos dos periódicos}

\begin{tabular}{|c|c|}
\hline $\begin{array}{l}\text { Literatura e ensino: ensino de } \\
\text { literatura (Descritores/temas ensino } \\
\text { de literatura e literatura e ensino). }\end{array}$ & $\begin{array}{l}\text { O ensino de literatura: ler, ouvir, colaborar e } \\
\text { conhecer ou "O testamento de Clara" } \\
\text { (2006); } \\
\text { Vãs querelas e verdadeiros objetivos do } \\
\text { ensino da literatura na França" (2007); } \\
\text { Literatura e ensino: notas quixotescas da } \\
\text { fronteira (2008); } \\
\text { Enseñanza de la literatura: de teorías y } \\
\text { lecturas (2010); } \\
\text { Escola e leitura: Carlos Drummond de } \\
\text { Andrade no livro didático (2012); } \\
\text { Literature and communicative competence: } \\
\text { a wrong assorted matrimony? (2014); } \\
\text { As dicotomias da leitura na educação básica: } \\
\text { reflexões sobre o "literário" e o "não } \\
\text { literário" (2016). }\end{array}$ \\
\hline $\begin{array}{l}\text { Ensino de literatura e formação de } \\
\text { leitores (Descritores/ temas: Ensino } \\
\text { de literatura e formação de leitores). }\end{array}$ & $\begin{array}{l}\text { A leitura e o espaço do prazer: um estudo } \\
\text { sobre as práticas docentes" (1997); } \\
\text { Ensino de literatura: a hora e a vez do leitor } \\
\text { (2009); } \\
\text { Audiolivro: um suporte para a educação } \\
\text { literária" (2010); } \\
\text { Um problema de formação: reflexões sobre } \\
\text { literatura, leitura e ensino (2011); } \\
\text { Formador de leitores, formador de } \\
\text { professores: a trajetória de Max Butlen } \\
\text { (2015); } \\
\text { Literatura na Educação Infantil: modos de } \\
\text { trabalho com textos e possibilidades do } \\
\text { desenvolvimento da capacidade criativa } \\
\text { (2016). }\end{array}$ \\
\hline $\begin{array}{l}\text { Ensino literário e letramento } \\
\text { literário (Descritores/temas: Ensino } \\
\text { literário e letramento literário). }\end{array}$ & $\begin{array}{l}\text { A “leitura literária" e a outra nas vozes do } \\
\text { currículo e dos programas" (2005); } \\
\text { Por um ensino literário complexo (2014); } \\
\text { O Partido Conservador e a educação literária } \\
\text { no Império brasileiro } 1841-1863 \text { (2015); } \\
\text { Letramento literário na formação inicial do } \\
\text { professor (2015). }\end{array}$ \\
\hline \multicolumn{2}{|l|}{ Fonte: (SILVA, 2018) } \\
\hline
\end{tabular}

Realizamos, também, um gráfico contendo o número de ocorrências dos temas/descritores a partir dos títulos, palavras-chaves, 
resumos e considerações finais dos artigos. Por meio deste gráfico, pudemos perceber a ocorrência de uma formação discursiva temática (MAINGUENEAU, 2015) do ensino de literatura.

\section{Número de ocorrências dos descritores/temas}

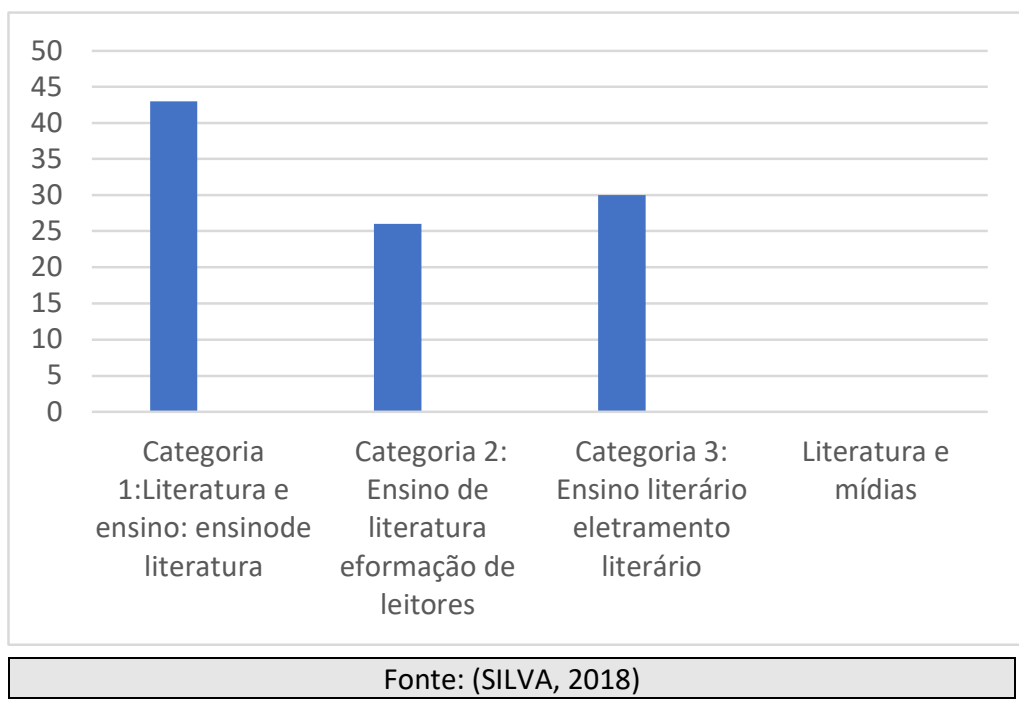

Levamos em consideração os descritores "ensino de literatura" e "literatura e ensino" para constituir a categoria Literatura e ensino: ensino de literatura, que obteve 43 ocorrências. A junção do descritor "ensino de literatura" ao descritor "formação de leitores", resultando na categoria Ensino de literatura e formação de leitores, totalizou 26 ocorrências. E, por fim, os descritores "ensino literário e letramento literário" decorreu na categoria Ensino literário e letramento literário com 30 ocorrências.

Destacamos que por meio do descritor "literatura e mídias", não foi localizada nenhuma ocorrência para a palavra mídias; logo, não apontamos nos gráficos ou nas tabelas, com a finalidade de manter coerência ao descritor proposto para a busca. No entanto, encontramos, na leitura mais atenta dos artigos, a discussão da literatura em outro suporte, diferente do impresso, nos referimos ao caso da tecnologia audiolivro. Mas, o importante é chamar atenção para necessidade de ampliar o debate sobre a relação entre literatura e mídias/tecnologias, o que quer dizer considerar a questão das mídias e tecnologias como fenômenos sociais e culturais fundamentais para pensar ensino e aprendizagem em todas as áreas do 
conhecimento. Isso, aliás, configura uma preocupação mundial, como as políticas "numérique", na França, por exemplo, envolvidas nos desafios do ensino e da aprendizagem.

Os artigos da categoria Literatura e ensino: ensino de literatura consistem em problematizações e possíveis soluções para questão do ensino de literatura na Educação Básica e Educação Superior no Brasil e no Exterior. Visualizamos a categoria/tema "literatura e ensino" enquanto campo semântico das discussões do campo da Educação e das Letras. A partir da relação que se estabelece entre as palavras ensino de literatura, os artigos propõem transformações pedagógicas, políticas e institucionais para que possa haver uma ressignificação, por parte dos leitores desses textos, acerca da questão.

Assinalamos os artigos inseridos nesta categoria: $\mathrm{O}$ ensino de literatura: ler, ouvir, colaborar e conhecer ou "O testamento de Clara" (2006); Vãs querelas e verdadeiros objetivos do ensino da literatura na França (2007); Literatura e ensino: notas quixotescas da fronteira (2008); Enseñanza de la literatura: de teorías y lecturas (2010); Escola e leitura: Carlos Drummond de Andrade no livro didático (2012); Literature and communicative competence: a wrong assorted matrimony? (2014); As dicotomias da leitura na educação básica: reflexões sobre o "literário" e o “não literário" (2016).

A partir da análise desses artigos, percebemos uma defesa da leitura literária de forma crítica: ensinar/literatura é promover criticidade, alteridade e subjetividade por meio da leitura das mais diversas manifestações literárias. $O$ ensino de literatura baseia-se em criar um espaço de prazer com a literatura, estabelecendo leituras e estudos do texto literário.

Os artigos inseridos na categoria Ensino de literatura e formação de leitores trazem em comum a temática formação de leitores. Ao reconhecer a temática "formação de leitores" como categoria específica das discussões do ensino de literatura, tais artigos ponderam o que significa formar leitores de literatura e a importância de a comunidade acadêmica/educacional atentar-se a essa questão.

Os artigos inseridos nesta categoria intitulam-se: A leitura e o espaço do prazer: um estudo sobre as práticas docentes (1997); Ensino de literatura: a hora e a vez do leitor (2009); Audiolivro: um suporte para a 
educação literária (2010); Um problema de formação: reflexões sobre literatura, leitura e ensino (2011); Formador de leitores, formador de professores: a trajetória de Max Butlen (2015).

Há um discurso que visa legitimar a importância de formar leitores de literatura, o que implica contribuir para formação de um sujeito crítico e autônomo. Nesta perspectiva, cabe ao professor de língua portuguesa contribuir para aumentar a capacidade leitora dos alunos, direcionando as leituras, interpretações e visões dos textos literários escolarizados/não escolarizados.

Os artigos inseridos na categoria Ensino literário e letramento literário trazem em comum o tema do ensino literário ou letramento literário como discussão específica do campo da Educação e das Letras, no que diz respeito ao ensino de literatura. Tais textos abordam propostas metodológicas e teóricas para a literatura e seu ensino. São eles: A “leitura literária" e a outra nas vozes do currículo e dos programas (2005); Por um ensino literário complexo (2014); O Partido Conservador e a educação literária no Império brasileiro 1841-1863 (2015); Letramento literário na formação inicial do professor (2015).

Nessa categoria há a ponderação sobre a importância do ensino literário e do letramento literário na Educação Básica, o que significa proporcionar práticas culturais, de leitura letrada e de letramento literário. À educação literária cabe proporcionar ao aluno o desenvolvimento de competências para realizar a leitura e, consequentemente, possibilidades de crítica e de autonomia com o texto literário.

Todavia, para se pensar a respeito das três tendências, realizamos um levantamento dos teóricos que se repetem em cada uma das três categorias. Na primeira categoria, verificamos a predominância de teóricos como AMARILHA, M; BAKHTIN, M; CALVINO, I; CHARTIER, R; CUESTA, C; DALVI, M. A; ECO, E; HAWKING, S; LAJOLO, M; MORTATTI, M. R. L; ABREU, M; ALVAREZ, G; BOMBINI, G; BRANDÃO, H. M. B; CANDIDO, A; CHOPPIN, A; GALEANO, E; ISER, W; HOUDART-MEROT, V; MENDONÇA, M; SANT'ANNA, A. $\mathrm{R}$; SCHOLES, R; VAN DIJK, T; ZILBERMAN, R.

Na segunda categoria, os estudiosos que aparecem mais de uma vez são Maurice BLANCHOT, M; EAGLETON, T; CHARTIER, R; ZILBERMAN, R. Já na terceira categoria, verificam-se BAKHTIN, M; BUESCU, H. C; CANDIDO, A; COELHO, M. C; KLEIMAN, A; MORIN, E; SOUZA, R. A; e ZILBERMAN, R. Tais 
teóricos parecem ser os agentes centrais do Campo da Educação e das Letras no processo de composição de ideário a respeito da literatura e seu ensino.

\section{Consideraçồes finais}

Após discussão sobre ensino de literatura e suas perspectivas nos periódicos acadêmicos Educação e pesquisa e Leitura: teoria e prática, no período de 1997 a 2016, pudemos organizar, sistematicamente, os artigos levantados em categorias que apontam tendências desse ensino nesses campos, a saber: Literatura e ensino: ensino de literatura; Formação de leitor: ensino de literatura; Leitura literária: letramento literário.

Ressaltamos, ainda, que no caso específico do tal diálogo entre o campo literário e o ensino, as perspectivas do ensino de literatura se aproximam muito do conceito de metodologias de ensino.

O levantamento permitiu abordar e discutir a respeito dos embates, produção de ideários e posicionamentos no interior dos campos da Educação e da Letras, tendo em vista recorrências do assunto e filiações de autores, por exemplo, propiciadas a partir de buscas realizadas por descritores como ensino de literatura; literatura e ensino; ensino de literatura e tecnologias; ensino de literatura e mídias; literatura e mídias; ensino de literatura e formação de leitores; ensino literário e letramento literário.

Dessa forma, destacamos artigos, em maior ou menor número, que tratam o ensino de literatura, o letramento literário, a formação do leitor e a leitura literária, no entanto, não encontramos artigos que abordem, diretamente, a relação do ensino de literatura com as mídias, o que temos é um debate isolado realizado sobre a tecnologia audiolivro, o que toca, enfim, na questão da literatura veiculada a um suporte diferente do impresso. Reiteramos, dessa forma, a necessidade de ampliar essa discussão.

Em relação à distribuição dos artigos e tendências sobre ensino de literatura, temos, dos dezessete artigos estudados, 31\% de autores do exterior; $31 \%$ da região Sudeste; $18 \%$ da região Nordeste; $12 \%$ da CentroOeste; e na região Sul do Brasil, $12 \%$.

Finalmente, fica-nos claro que entender as lógicas do campo nos permite perceber e compreender posições e confrontos sobre o tema 
ensino de literatura e a partir daí buscar estratégias e posicionamentos mais definidos, no que se refere ao assunto e suas implicações com a sala de aula e a formação de professores de literatura.

Anexo: quadro de referência dos artigos mapeados

\begin{tabular}{|c|c|c|c|}
\hline \multicolumn{4}{|c|}{ Revista Educação e Pesquisa } \\
\hline $\begin{array}{l}\text { BUENO, B. O; DE } \\
\text { REZENDE, N. L. } \\
\text { Formador de } \\
\text { leitores, formador } \\
\text { de professores: a } \\
\text { trajetória de Max } \\
\text { Butlen. Educação e } \\
\text { pesquisa, São Paulo, } \\
\text { v. 41, p. 543-564, } \\
2015 \text {. }\end{array}$ & $\begin{array}{l}\text { OLIVEIRA, L. E. O } \\
\text { Partido } \\
\text { Conservador e a } \\
\text { educação literária } \\
\text { no Império } \\
\text { brasileiro (1841- } \\
\text { 1863). Educação e } \\
\text { pesquisa, São } \\
\text { Paulo, v. 41, p. } \\
\text { 934-956, 2015. }\end{array}$ & $\begin{array}{l}\text { TRONCOSO ARAOS, } \\
\text { X. Literature and } \\
\text { communicative } \\
\text { competence: a } \\
\text { wrong assorted } \\
\text { matrimony? } \\
\text { Educação e pesquisa, } \\
\text { São Paulo, v. 40, p. } \\
\text { 1015-1028, 2014. }\end{array}$ & $\begin{array}{l}\text { VERRIER, J. Vãs } \\
\text { querelas e } \\
\text { verdadeiros } \\
\text { objetivos do ensino } \\
\text { da literatura na } \\
\text { França. Educação e } \\
\text { pesquisa, v. } 33, \text { p. } \\
207-213,2007 .\end{array}$ \\
\hline \multicolumn{4}{|c|}{ Revista Leitura: teoria e prática } \\
\hline $\begin{array}{l}\text { AMARILHA, M. O } \\
\text { ensino de literatura: } \\
\text { ler, ouvir, colaborar } \\
\text { e conhecer ou “O } \\
\text { testamento de } \\
\text { Clara”. Leitura: } \\
\text { teoria e prática, } \\
\text { Campinas, n. 46, p. } \\
25-30,2006 .\end{array}$ & $\begin{array}{l}\text { BRANCO, A. A" } \\
\text { Leitura Literária" e } \\
\text { a Outra nas Vozes } \\
\text { do Currículo e dos } \\
\text { programas. } \\
\text { Leitura: teoria e } \\
\text { prática, Campinas, } \\
\text { n. } 45, \text { p. } 5-15 \text {, } \\
2005 .\end{array}$ & $\begin{array}{l}\text { BRITO, L. E. B et al. } \\
\text { Literatura na } \\
\text { Educação Infantil: } \\
\text { modos de trabalho } \\
\text { com textos e } \\
\text { possibilidades da } \\
\text { capacidade criativa. } \\
\text { Leitura: teoria e } \\
\text { prática, Campinas, n. } \\
68, \text { p. } 45-64,2016 .\end{array}$ & $\begin{array}{l}\text { CUESTA, C. } \\
\text { Enseñanza de la } \\
\text { literatura: de } \\
\text { teorías y lecturas. } \\
\text { Leitura: teoria e } \\
\text { prática, Campinas, } \\
\text { n. 55, p.5-11, } 2010 .\end{array}$ \\
\hline $\begin{array}{l}\text { DALVI, M. A. Escola } \\
\text { e leitura: Carlos } \\
\text { Drummond de } \\
\text { Andrade no livro } \\
\text { didático. Leitura: } \\
\text { teoria e prática, } \\
\text { Campinas, n.58, p. } \\
\text { 52-59, 2012. }\end{array}$ & $\begin{array}{l}\text { DE SÁ, A. P. S. As } \\
\text { dicotomias da } \\
\text { leitura na } \\
\text { educação básica: } \\
\text { reflexões sobre o } \\
\text { "literário" e o “não } \\
\text { literário". Leitura: } \\
\text { teoria e prática, } \\
\text { Campinas, n.66, p. } \\
\text { 111-124, 2016. }\end{array}$ & $\begin{array}{l}\text { DE SOUZA, M. S. D; } \\
\text { CELVA, R.; } \\
\text { HELVADJIAN, V. } \\
\text { Audiolivro: um } \\
\text { suporte para a } \\
\text { educação literária. } \\
\text { Leitura: teoria e } \\
\text { prática, Campinas, n. } \\
\text { 55, p. 28-36, 2010. }\end{array}$ & $\begin{array}{l}\text { MORTATTI, M. R. L. } \\
\text { Literatura e ensino: } \\
\text { notas ¿quixotescas? } \\
\text { Da fronteira. } \\
\text { Leitura: teoria e } \\
\text { prática, Campinas, } \\
\text { n. } 51 \text {, p. } 25-31 \text {, } \\
2008 .\end{array}$ \\
\hline $\begin{array}{l}\text { PINTO, F. N. P. Por } \\
\text { um ensino literário } \\
\text { complexo. Leitura: } \\
\text { teoria e prática, } \\
\text { Campinas, n. 62, p. } \\
\text { 115-127, 2014. }\end{array}$ & $\begin{array}{l}\text { ROLLA, A. R. A } \\
\text { leitura e o espaço } \\
\text { do prazer: um } \\
\text { estudo sobre as } \\
\text { práticas docentes. } \\
\text { Leitura: teoria e } \\
\text { prática, Campinas, } \\
\text { n. } 30, \text { p.45-54, } \\
1997 .\end{array}$ & $\begin{array}{l}\text { ROSSI, M. A. L; } \\
\text { PERES, S. M. } \\
\text { Letramento literário } \\
\text { na formação inicial } \\
\text { do professor. } \\
\text { Leitura: teoria e } \\
\text { prática, Campinas, n. } \\
\text { 65, p. 99-113, } \\
2015 .\end{array}$ & $\begin{array}{l}\text { SANTOS, R. C. } \\
\text { Ensino de literatura: } \\
\text { a hora e vez do } \\
\text { leitor. Leitura: } \\
\text { teoria e prática, } \\
\text { Campinas, n. } 53 \text {, } \\
\text { p.24-30, 2009. }\end{array}$ \\
\hline $\begin{array}{l}\text { SUTTANA, R. Um } \\
\text { problema de } \\
\text { formação: reflexões } \\
\text { sobre literatura, } \\
\text { leitura e ensino. } \\
\text { Leitura: teoria e } \\
\text { prática, Campinas, } \\
\text { n. } 57, \text { p. } 66-77,2011\end{array}$ & & & \\
\hline
\end{tabular}




\section{Referências}

ANDRÉ, M. E. D. A. Etnografia da Prática Escolar. Campinas: Papirus, 2005.

BAKHTIN, M. Questões de literatura e de Estética. A teoria do romance. São Paulo: Unesp, 1988.

BARDIN, L. Análise de conteúdo. Lisboa: Edições 70, 1977.

BOURDIEU, P. Algumas Propriedades dos Campos. Questões de sociologia. Rio de Janeiro: Marco Zero, 1983.

CATANI, D. B. A imprensa periódica educacional: as revistas de ensino e o estudo do campo educacional. Educação e Filosofia, Uberlândia, Minas Gerais, v. 10, n. 20, p. 115-130, 1996.

CATANI, D. B.; VILHENA, C. P. S. A imprensa periódica educacional e as fontes para a história da cultura escolar brasileira. Revista do Instituto de Estudos Brasileiros, São Paulo, v. 37, p. 177-183, 1994.

EDUCAÇÃO E PESQUISA. São Paulo: Ed. FEUSP, 1975. Anual.

FERREIRA, N. S. A. Pesquisa em leitura: Um estudo dos resumos de dissertações de mestrado e teses de doutorado defendidas no Brasil, de 1980 a 1995. 1999. Tese. (Doutorado em Educação) Universidade Estadual de Campinas, Campinas.

FERREIRA, N. S. A. As pesquisas denominadas "estado da arte". Educação \& Sociedade, São Paulo, ano 23, n. 79, p. 257-272, 2002.

LEITURA: TEORIA E PRÁTICA. Campinas: Ed. Associação de Leitura do Brasil, 1982. Trimestral.

MAINGUENEAU, D. Discurso e análise do discurso. Trad. Sírio Possenti. São Paulo: Parábola Editorial, 2015.

SILVA, G.B.V. Formação de professores em Letras: o ensino de literatura em periódicos brasileiros. 2018. 76 f. Relatório Final FAPESP- Fundação de Amparo à Pesquisa do Estado de São Paulo (Iniciação Científica Proc. 2016/12706-3) - Universidade Estadual de São Paulo, Assis- São Paulo, 2018. 